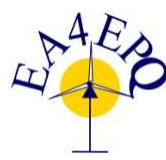

International Conference on Renewable Energies and Power Quality (ICREPQ'13)

Bilbao (Spain), 20 ${ }^{\text {th }}$ to $22^{\text {th }}$ March, 2013

Renewable Energy and Pourer Quality. Fournal (RE\&PQJ)

ISSN 2172-038 X, No.11, March 2013

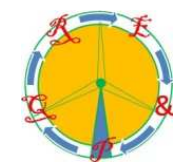

\title{
On line monitoring of transmission line
}

\author{
Dr. A. K. Sinha, Manish Yadav, K. Tudu, H. Rathore, B. Kumar \\ Dept. of Electrical Engineering \\ NIT Silchar, India \\ ashokesinha@2001yahoo.co.in
}

\begin{abstract}
Continuous online monitoring of transmission line is required for proper functioning of power system. This paper presents two simulink model one for single transmission line, singly fed and the other for parallel transmission line doubly fed and presents the simulation result which shows the continuous variation in transmission line impedance before, during and after the fault. This paper shows the effect of different factors like prefault system condition, ground fault resistance, series compensation effect individually and then taking together on impedance plot under line to ground fault and three phase to ground fault. In case of parallel transmission line the paper have taken into account of mutual coupling effect also.
\end{abstract}

Index Terms - series compensation, parallel lines, R-X plot, mutual coupling effect, protective relay, type of fault, distance protection.

\section{INTRODUCTION}

The capital investment involved in a power system for the generation , transmission and distribution of electrical power is so great that proper precautions must be taken to ensure that the equipment not only operates to its peak efficiencies but also that it is protected from different kind of faults. The continuous online monitoring of transmission line is required to operate the correct circuit breakers so as to disconnect only the faulty equipment from the system as fast as possible, thus minimizing the trouble and damage caused by faults when they occur.

\section{POWER TRANSMISSION LINE}

A. Single Transmission Lines Equipped with Series Compensation

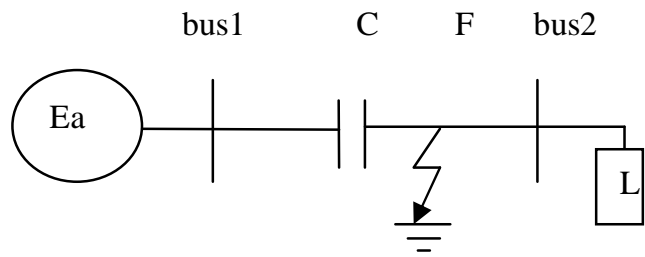

Fig:1 Single Transmission Lines Equipped with Series Compensation Capacitors

Series compensation is used to meet maximum power demand and to improve stability limit of power. In order to meet the high demand for power transmission capacity series capacitors are installed on power transmission lines. This allows the impedance of the line to be lowered, thus yielding increased transmission capability. The series capacitor makes sense because it's simple and it can provide the benefits of increased system stability, reduced system losses, and better voltage regulation. Protective distance relays, which make use of impedance measurements in order to determine the presence and location of faults, are "fooled" by installed series capacitance on the line when the presence or absence of the capacitor in the fault circuit is not known a priori. This is because the capacitance cancels or compensates some of the inductance of the line and therefore the relay may perceive a fault to be in its first zone when the fault is actually in the second or third zone of protection [1].

\section{B. Distance protection aspect for parallel transmission line}

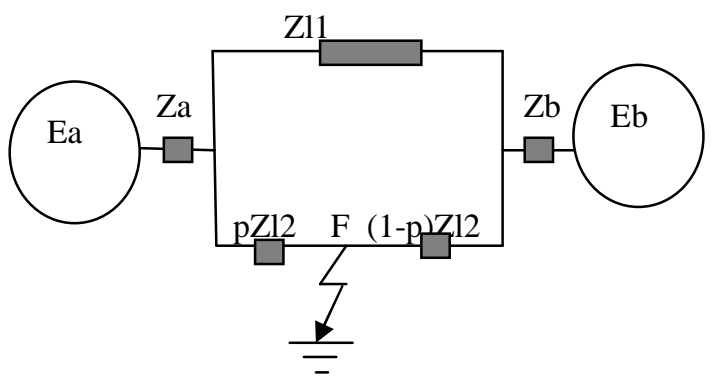

Fig.2 Parallel Transmission line

In general the relay algorithm are designed without considering the effects like series compensation, mutual coupling in case of parallel transmission line. In a single-line system, the measured voltage is proportional to the positive and zero sequence impedance during a single-phase-to ground 
fault. But, in two-terminal parallel lined systems, this voltage is affected by the zero-sequence mutual impedance between the two lines, which can lead to an error in the estimated impedance. Mutual coupling affects the accuracy of the results and it will produce under-reach or overreach [2] . The fault resistance, on the other hand, is an operational problem and depends upon various factors, such as voltage level, tower footing resistance, soil resistivity, etc. The study of power system of relays requires some previous experience in this field. Laboratories focusing on teaching and researching the area of power-system protection have therefore been amply reported[3]. Faults cause aberrations in the currents and voltages. At fault inception a sudden rise or drop in voltage can occur. Current and voltage peaks can change in magnitude and/or phase position with respect to prefault conditions[4]. SIMULINK, now incorporated into MATLAB, can also be used to analyze and design of power systems. During last four decade's simulation of power systems have gained more importance. Recently published IEEE paper discussing different approaches to modeling protective relays and related power system events indicates a variety of possible software tools that may be used for this purpose [5].

\section{Transmission Line Faults}

In transmission lines with a three-phase power source, there are ten types of faults that can occur. The faults in the order of decreasing frequency of occurrence are: three single-phase-toground faults (1LGs), three phase-to-phase faults (2Ls), three double-phase-to-ground faults (2LGs), and a three-phase fault (3Ls). Single line to ground faults (1LG) occur when one of the phases is shortened to the ground. During the fault the impedance, $\mathrm{Z}_{\mathrm{fag}}$, is not necessarily zero (bolted) but it might have a non-zero impedance but still much smaller than the line impedance. The magnitude of current in a faulty line rises significantly higher than the normal operative current while the voltage does not go through significant change in magnitude.

\section{Protective Relay}

There are three types of relays:

Electromechanical relays :The first relay developed used electrical and mechanical devices or a combination of both to switch the breaker.

Solid-state relays: Solid state relays us semiconductors and ICs to operate. It is a migration to electronic relays, which gives advantages such as smaller size, more accurate, and is easier to change the characteristics of the relay.

Digital relays :Digital relays use processor to do numerical analysis on the digitised data. Digital relays are modular and can be integrated with other protection functions

\section{E. Impedance Detection}

The impedance detection based its fault detection on the fact that the input impedance of a transmission line changes when a fault occurs. The magnitude of the impedance varies according to the location of the fault from the relay monitoring it, thus it is called distance relay. Distance relay does not need to compare the measurement between two ends of protection zone as in over current relays. However, distance relay needs current and voltage as input. Impedance Detection : magnitude of the fault upon which the tripping decision is made. In threephase electric power systems, method of symmetrical components provides simpler analysis for power system performance during unbalanced faults (1LGs, 2LGs, 2Ls). Symmetrical components consist of positive, negative and zero sequence of currents and voltages Symmetrical components analysis is an important tool in analysing the impedance in a distance relay. Horowitz (1995) shows that for both unbalanced and balanced (3Ls) faults, the distance relay will always measure the positive sequence impedance to the fault.

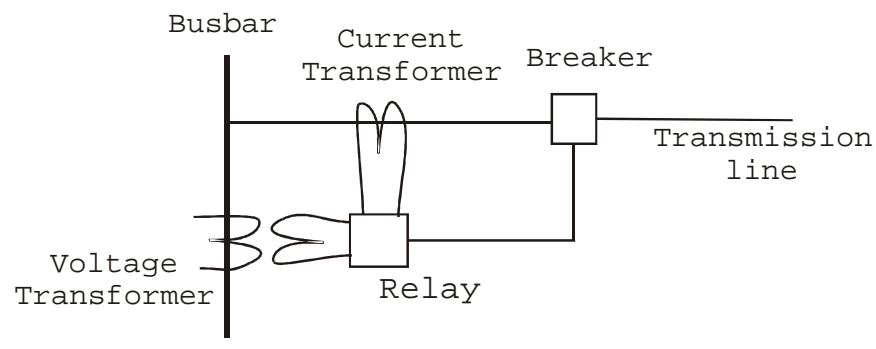

Fig(3): impedance detection

The position of one value of $\mathrm{Z}$ (line impedance) is shown in figure(4) with angle $\Theta$ with the R-axis. This means that the current lags the voltage by angle $\Theta$. In case the two curve i.e. current and voltage are in phase, the Z-vector would coincide with R-axis. In case the current was lagging the voltage by $180^{\circ}$,the $\mathrm{Z}$-vector would coincide with the $-\mathrm{R}$ axis. It is to be noted that $-\mathrm{R}$ axis does not mean here negative resistance axis but the one as explained. When current lags behind voltage the $\mathrm{Z}$-vector lies in upper semi-circle and $\mathrm{Z}$ lies in the lower when current leads the voltage.

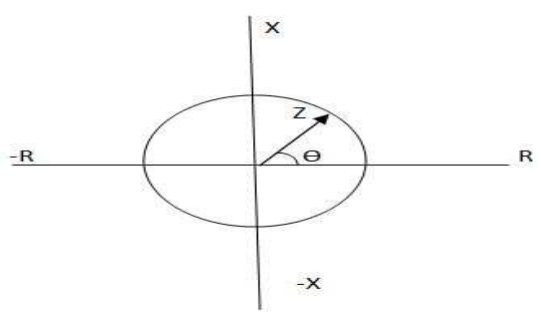

Fig(4): R-X plot 


\section{F. Mathematical Background}

In this approach the estimation is based on equation $\mathrm{Z}=\mathrm{V} / \mathrm{I}$. The sampled current and voltage signal are initially transformed into phasor quantities and than phasor quantities are converted into complex quantities. Signal at any given time may be described by a phasor. Phasor actually is a vector rotating in the complex plane with a speed $\omega$ radian/sec, a snap-shot in time, the signal at that time, $\mathrm{X}(\mathrm{t})$ is given in rectangular form by; (Marven \& Gillian, 1993)

$\mathrm{X}(\mathrm{t})=\mathrm{a}+\mathrm{jb}$

Let the two vectors be given by

Voltage vector $\mathrm{V}=\mathrm{a} 1+\mathrm{jb} 1$;

Current vector $\mathrm{I}=\mathrm{a} 2+\mathrm{jb} 2$;

$\mathrm{Z}=\mathrm{v} / \mathrm{I}=(\mathrm{a} 1+\mathrm{jb} 1) /(\mathrm{a} 2+\mathrm{jb} 2)$

$=(\mathrm{a} 1+\mathrm{jb} 1)(\mathrm{a} 2-\mathrm{jb} 2) /(\mathrm{a} 2+\mathrm{jb} 2)(\mathrm{a} 2-\mathrm{jb} 2)$

$=(\mathrm{a} 1 \mathrm{a} 2+\mathrm{b} 1 \mathrm{~b} 2)+\mathrm{j}(\mathrm{b} 1 \mathrm{a} 2-\mathrm{a} 1 \mathrm{~b} 2) /\left(\mathrm{a} 2^{\wedge} 2+\mathrm{b} 2^{\wedge} 2\right)$

Therefore

$\mathrm{Z}=\mathrm{R}+\mathrm{j} \mathrm{X}=(\mathrm{a} 1 \mathrm{a} 2+\mathrm{b} 1 \mathrm{~b} 2)+\mathrm{j}(\mathrm{b} 1 \mathrm{a} 2-\mathrm{a} 1 \mathrm{~b} 2) /\left(\mathrm{a} 2^{\wedge} 2+\mathrm{b} 2^{\wedge} 2\right)$

Therefore $\mathrm{R}=(\mathrm{a} 1 \mathrm{a} 2+\mathrm{b} 1 \mathrm{~b} 2) /\left(\mathrm{a} 2^{\wedge} 2+\mathrm{b} 2^{\wedge} 2\right)$

And $\mathrm{X}=(\mathrm{b} 1 \mathrm{a} 2-\mathrm{a} 1 \mathrm{~b} 2) /\left(\mathrm{a} 2^{\wedge} 2+\mathrm{b} 2^{\wedge} 2\right)$

\section{ANALYSIS OF SINGLE TRANSMISSION LINE}

Analysis of single transmission line:

1. under normal condition

a) without considering any effect

b) considering capacitive series compensation effect

2. single phase to ground fault

a) without considering any effect

b) considering capacitive series compensation effect

3. Three phase to ground fault

a) without considering any effect

b) considering capacitive series compensation effect

\section{G. MATLAB Simulink}

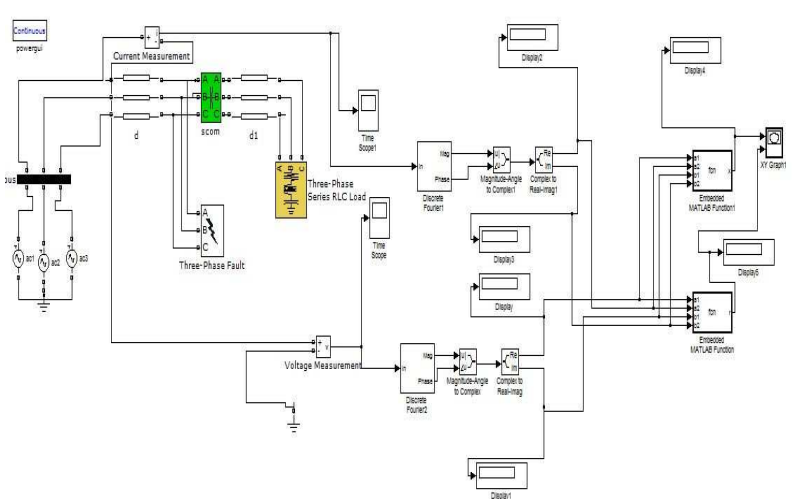

Fig: 5 Simulink model of single transmission line

\section{Under normal condition:}
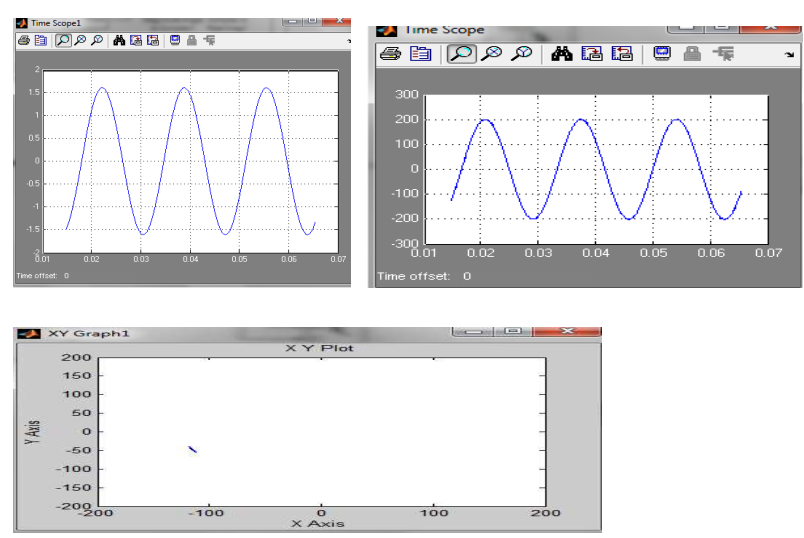

Fig 6 (a) without considering any effect

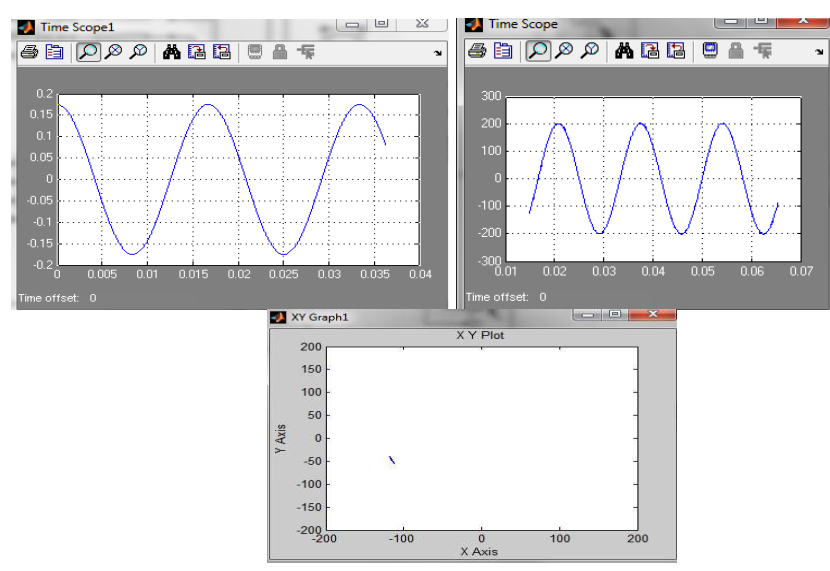

Fig 6 (b) considering capacitive series compensation effect

\section{Single phase to ground fault:}

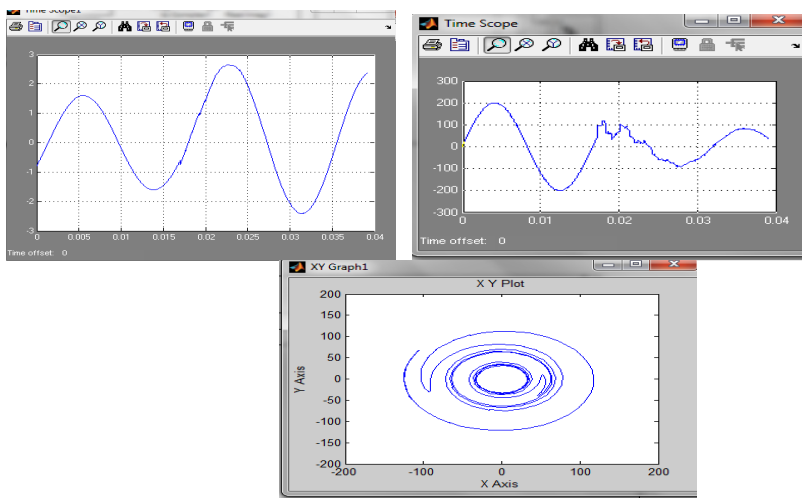

Fig 7 ( a) without considering any effect
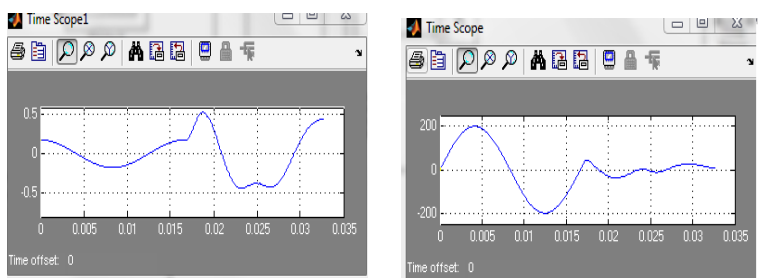


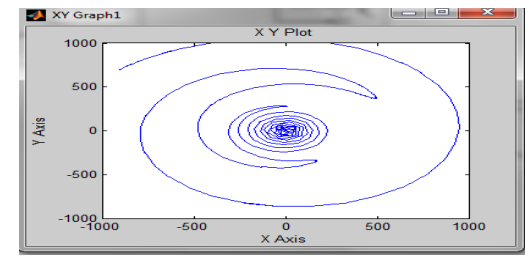

Fig 7 (b) considering capacitive series compensation effect

\section{Three phase to ground fault}

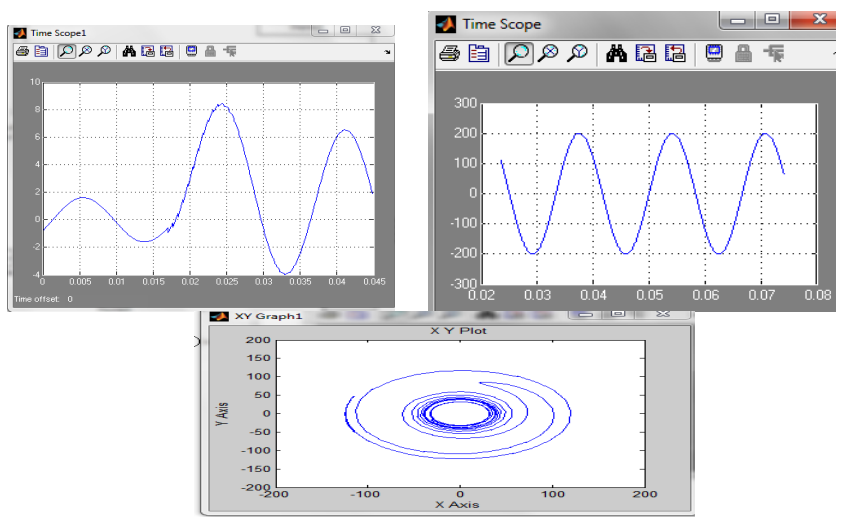

Fig 8 (a) without considering any effect
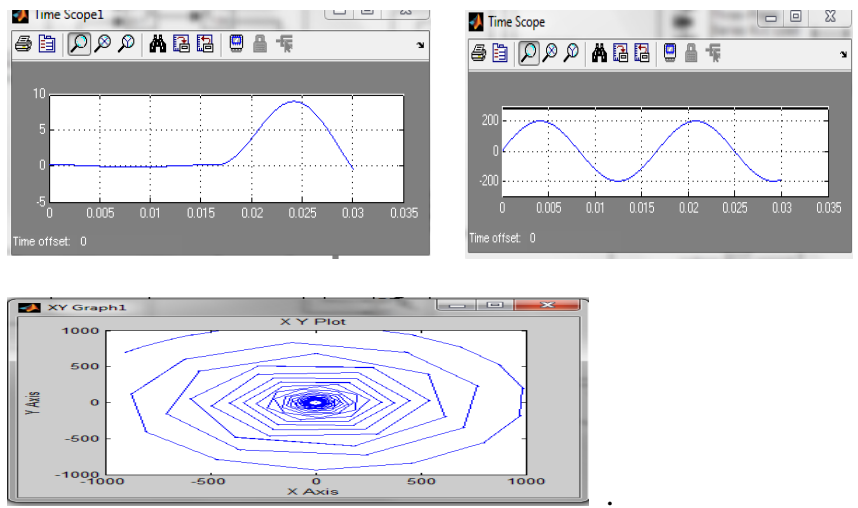

Fig 8(b) considering capacitive series compensation effect

From the above graph, the similarity of the waveforms between various fault types can be seen (note: ABCG was included for completeness).

The waveforms that have similarities are grouped as follows: (BG and $\mathrm{CG}),(\mathrm{AB}, \mathrm{BC}$, and $\mathrm{AC}),(\mathrm{ABG}, \mathrm{ACG}$, and $\mathrm{BCG})$, and ( $\mathrm{ABC}$ and $\mathrm{ABCG})$.

Based on the above information, the fault types included in the training data were $\mathrm{AG}, \mathrm{BG}, \mathrm{AB}, \mathrm{AC}, \mathrm{ABG}$, and $\mathrm{ABC}$.

\section{ANALYSIS OF PARALLEL TRANSMISSION LINE}

1. under normal condition

a) without considering any effect

b) considering mutual coupling effect

c) considering capacitive series compensation effect

d) considering mutual coupling and capacitive series compensation effect together

2. single phase to ground fault

a) without considering any effect

b) considering mutual coupling effect

c) considering capacitive series compensation effect

d) considering mutual coupling and capacitive series compensation effect together

3. under three phase to ground fault condition

a) without considering any effect

b) considering mutual coupling effect

c) considering capacitive series compensation effect

d) considering mutual coupling and capacitive series compensation effect together

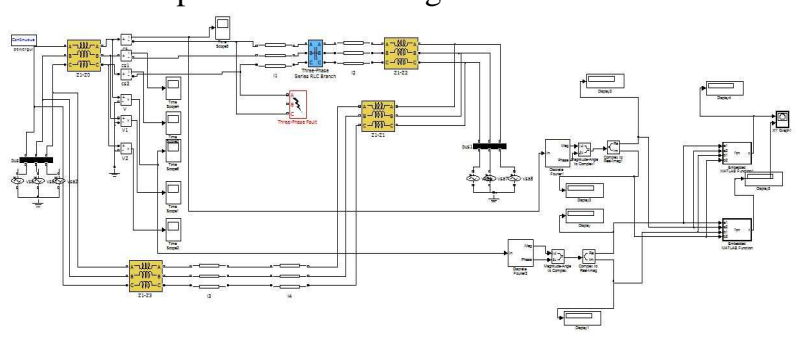

Fig:9 Simulink model of parallel transmission line

\section{1. under normal condition}

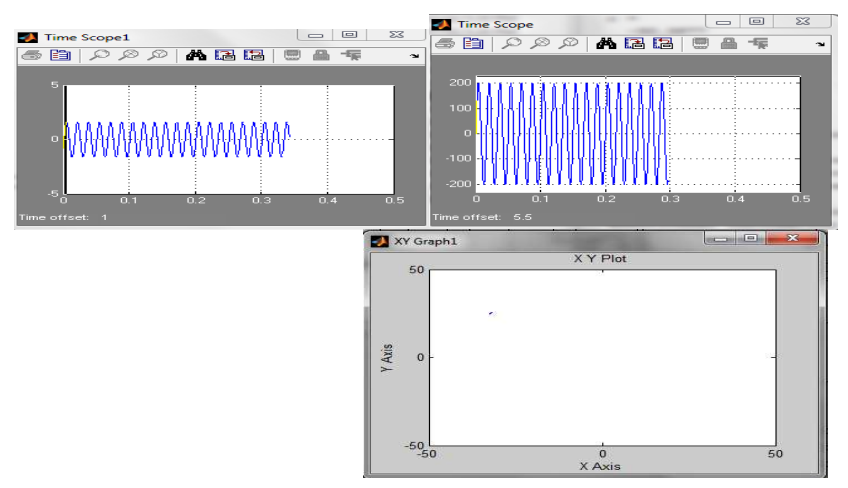

Fig 10( a) without considering any effect

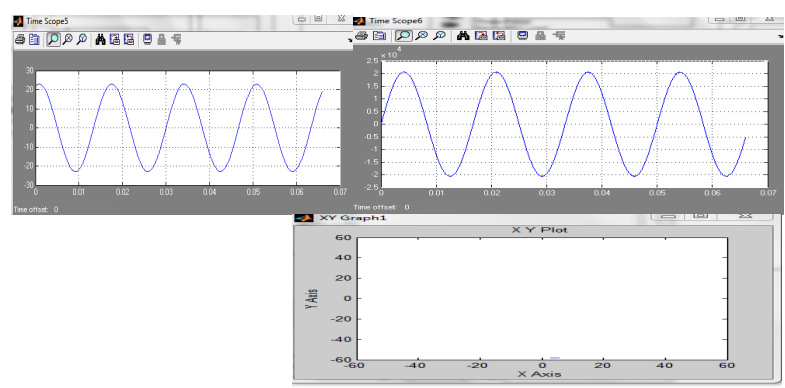

Fig 10(b) considering mutual coupling effect 


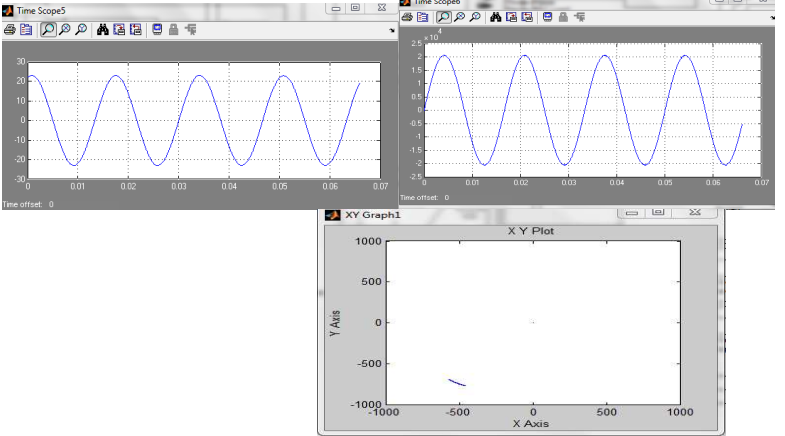

Fig 10 (c) considering capacitive series compensation effect

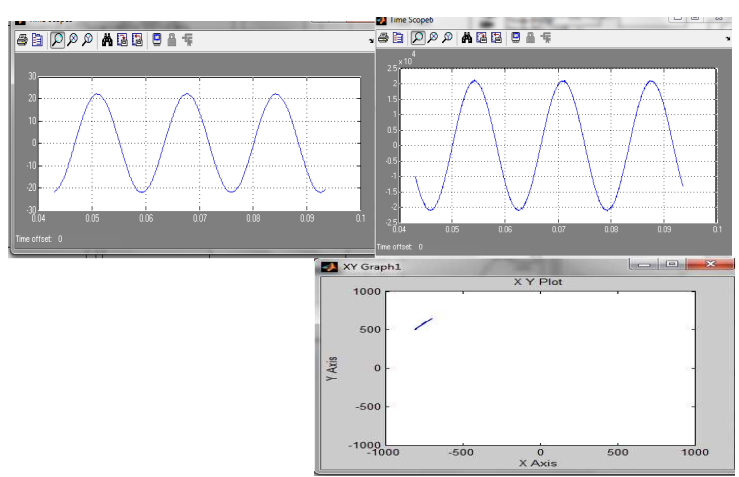

Fig 10(d) considering mutual coupling and capacitive series compensation effect together

\section{2.single phase to ground fault}
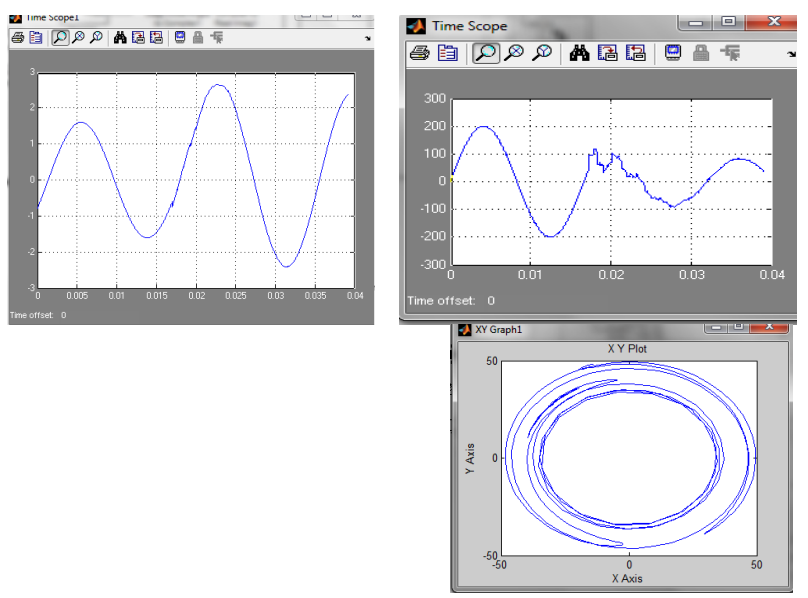

Fig11(a) without considering any effect

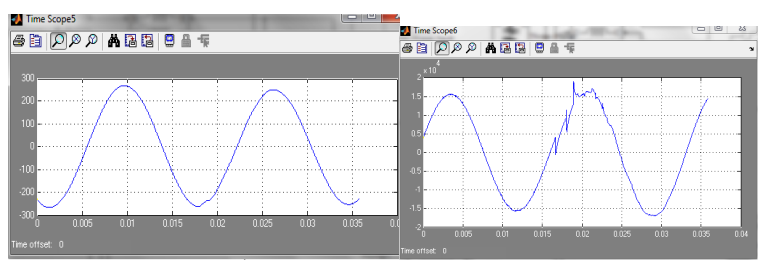

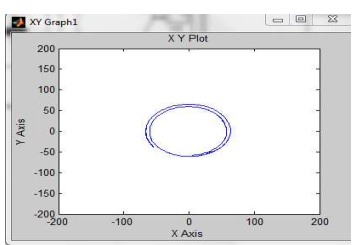

Fig 11(b) considering mutual coupling effect

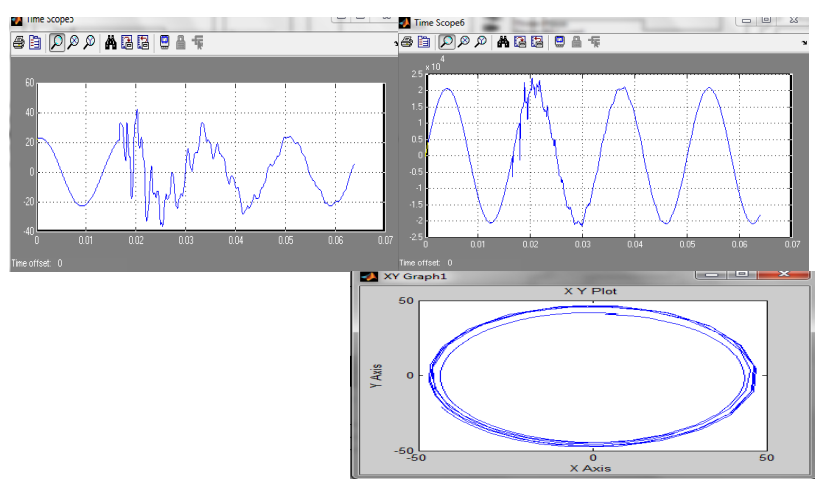

Fig 11(c) considering capacitive series compensation effect

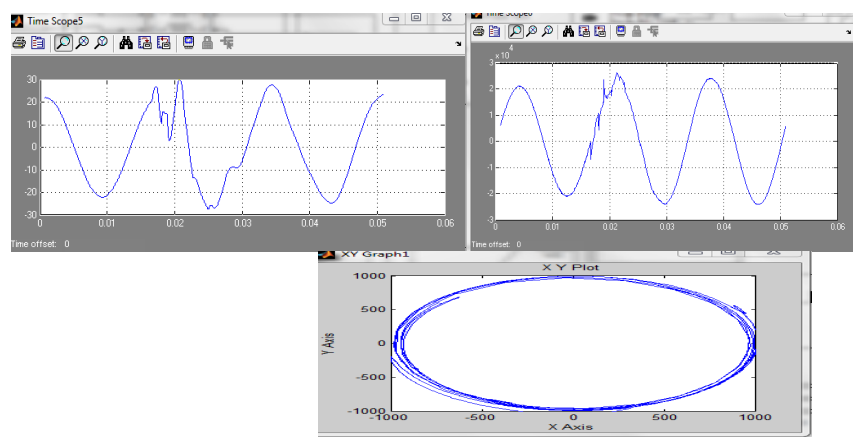

Fig 11(d) considering mutual coupling and capacitive series compensation effect together

\section{3. under three phase to ground fault condition}

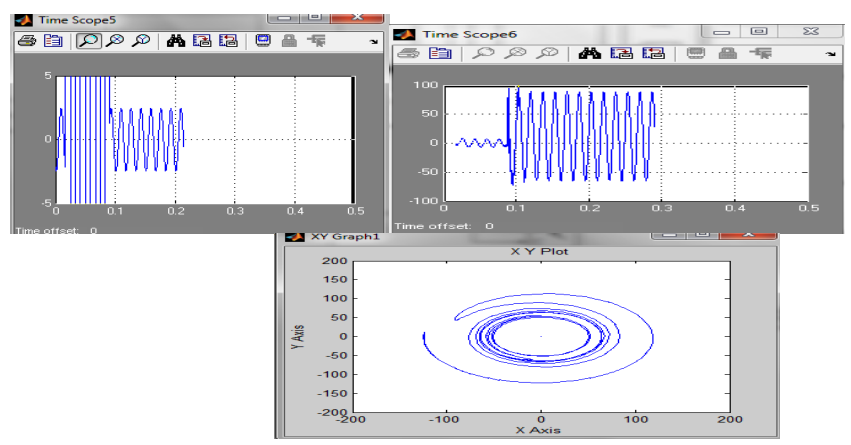

Fig 12(a) without considering any effect

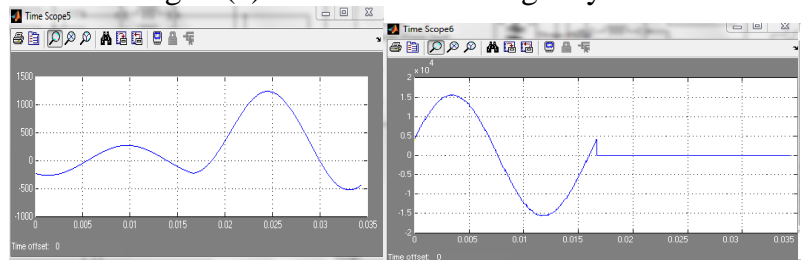




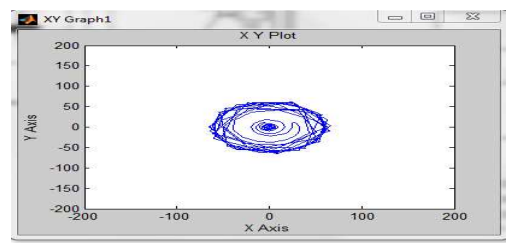

Fig 12(b) considering mutual coupling effect

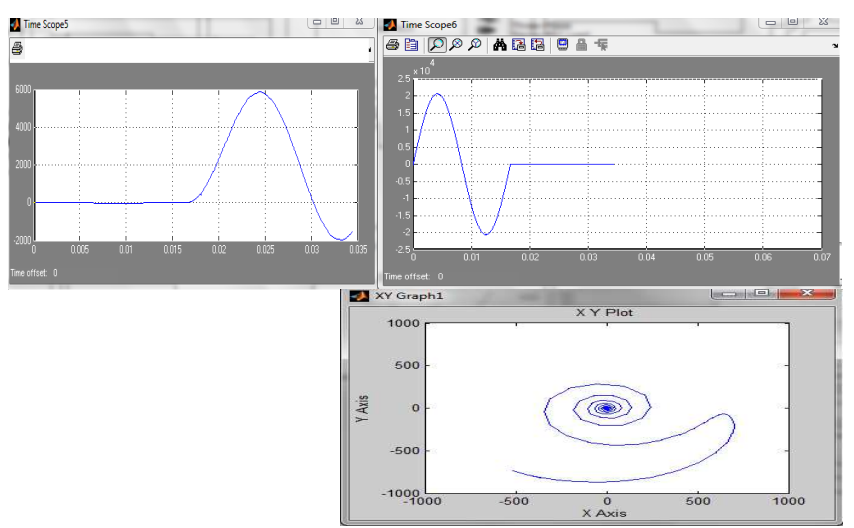

Fig 12(c) considering capacitive series compensation effect
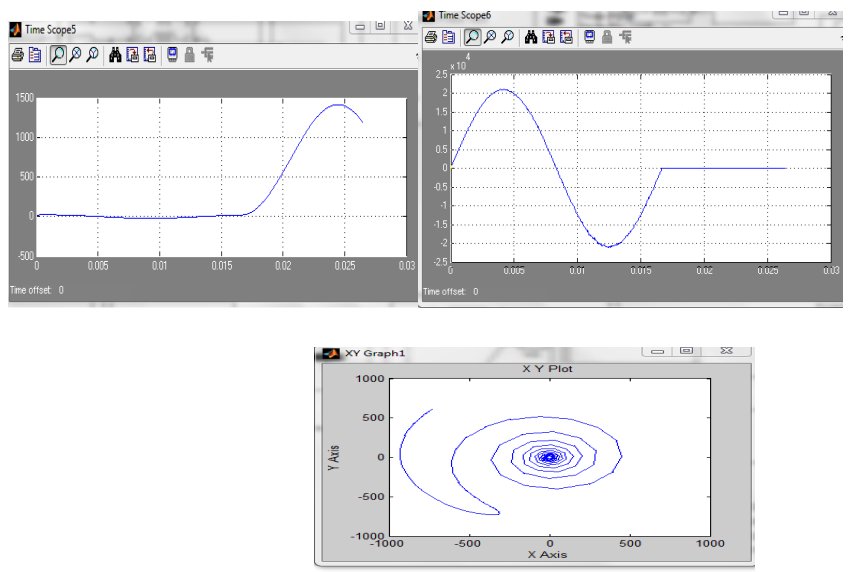

Fig 12( d) considering mutual coupling and capacitive series compensation effect together

From the different graphs obtained from the MATLAB Simulink Model can be seen that the voltage and current are in steady state under normal operating conditions and as the fault occurs in a line the current increases and voltage decreases. This results into decrease in impedence of the line.

\section{CONCLUSION}

Impedance seen by relay will depend upon the type of fault and also upon the factors like prefault system condition, ground fault resistance, series compensation effect, mutual coupling effect (in case of parallel transmission line) etc. and none of the above factor can be ignored while designing an efficient relay.The experiment presented can monitor the transmission line under normal and fault conditions for both single and parallel transmission line. It can be conclude that ere is effect of series compensation on single transmission line which may affect the reach accuracy of a relay and mutual coupling effect in case of parallel transmission line.

\section{ACKNOWLEDGMENT}

The authors are acknowledging with thanks to National Institute of Technology, Silchar, India for allowing us to work in Computational Laboratory of the Electrical Engineering Department.

\section{REFERENCES}

[1]. Dr. Arun G. Phadkeetc, "Distance Protection Aspects of Transmission Lines Equipped with Series Compensation Capacitors" Summers, September 29, 1999 Blacksburg, VA

[2]. J. Upendar etc, "Comprehensive Adaptive Distance Relaying Scheme for Parallel Transmission Lines" IEEE transactions on power delivery, vol. 26, no. 2, april 2011 .

[3]. V. Fernão Pires etc, "Distance-Learning Power-System Protection Based on Testing Protective Relays" IEEE TRANSACTIONS ON INDUSTRIAL ELECTRONICS, VOL. 55, NO. 6, JUNE 2008

[4] G. D. Rockfeller, "Fault Protection with a Digital Computer" IEEE Transaction on Power Apparatus ansd System, VOL. PAs-88, NO. 4, APRIL 1969

[5] P.G. McLaren etc, "Software Models for Relays," IEEE Transactions on Power Delivery, Vol. 16, No.2, pp. 238-246, April 2001

[6] The MathWorks, Inc., Power System Blockset User's Guide, Version 1, 1999

[7] G. Sybille and L.-H. Hoang, "Digital Simulation of Power Systems and Power Electronics using the MATLAB/SIMULINK Power System Blockset", IEEE/PES Winter Meeting, 2000, pp. 2973-2982.

[8] P. G. McLaren, I. Fernando, H. Liu, E. Dirks, G. W. Swift, and C. Steele, "Enhanced double circuit line protection," IEEE Trans. Power Del., vol. 12, no. 3, pp. 11001108, Jul. 1997.

[9] J. S. Thorp etc, "Feasibility of adaptive protection and control," IEEE Trans. Power Del., vol. 8, no. 3, pp. 975-983, Jul. 1993.

[10] K. K. Li and L. L. Lai, "Ideal operating regions of distance relay under high resistance earth fault," Elect. Power Syst. Res., vol. 43, pp. 215-219, 1997.

[11] B. R. Bhalja and R. P. Maheshwari, "High-resistance faults on two terminal parallel transmission line: Analysis, simulation studies and an adaptive distance relaying scheme," IEEE Trans. Power Del., vol. 22, no. 2, pp. 801-812, Apr. 2007.

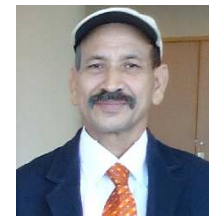

Dr. A. K. Sinha: received his B.E. and M. Tech. from VNIT, Nagpur in 1978 and 1981. Dr Sinha has received his Ph. D. from IIT, Kharagpur, India in 1990. His field of work is Multiprocessor based digital relays, Power Quality Monitoring and Signal processing. 